\title{
Electrochemical behavior and in-vitro antimicrobial screening of some thienylazoaryls dyes
}

\author{
Joseph Tsemeugne ${ }^{1,2}$, Emmanuel Sopbué Fondjo ${ }^{1 *} \mathbb{0}$, Jean-de-Dieu Tamokou ${ }^{3}$, Ignas Tonle ${ }^{1}$, \\ Irene Chinda Kengne ${ }^{3}$, Arnaud Djintchui Ngongang', Stephen Tamekou Lacmata ${ }^{3}$, Taoufik Rohand ${ }^{4}$, \\ Jules Roger Kuiate ${ }^{3}$ and Beibam Luc Sondengam²
}

\begin{abstract}
Background: A series of recently reported phenolic azo dyes $\mathbf{7 a - e}$ were prepared by coupling the thienyl diazonium sulfate of 3-Amino-4H-benzo[f]thieno[3,4-c](2H)chromen-4-one with selected diversely substituted phenolic and naphtholic derivatives. These compounds were evaluated for their antibacterial and antifungal activities. Furthermore their voltammetric behavior was compared at a glassy carbon electrode.

Results: The voltammetric behavior of the five recently reported azo dyes has been compared at a glassy carbon electrode. It is shown that the azo dyes $\mathbf{7 a - e}$ with a hydroxyl group in the ortho position with respect to the azo bridge give rise to well defined, irreversible peaks for the oxidation and reduction process within a pH range of 2-7. The mechanisms of electrochemical oxidation of compound $\mathbf{7 a - c}$ and $\mathbf{7 e}$ are proposed. For the hydroxyl-substituted dyes, re-oxidation peaks were obtained in the subsequent scan. The antimicrobial activities of the reported compounds 7a-e along with the entire precursors 1-4 and $\mathbf{6 a - e}$ were performed against selected bacterial and fungal species and their activities compared to those of nystatin, griseofulvin and ciprofloxacin used as reference drugs.

Conclusions: The present study showed significant antimicrobial activity of compounds $\mathbf{6 d}, \mathbf{7 a}$ and $\mathbf{7 c , e}$ against the tested microorganisms; this result confirms the antimicrobial potency of azo compounds and some of their precursors.
\end{abstract}

Keywords: Azo compounds, Carbon paste electrode, Cyclic voltammetry, Antibacterial agents, Antifungal agents

\section{Introduction}

Before the discovery of the first synthetic organic dye in 1856, namely the Mauvaine [1], human being has to use some part of plants like roots and leaves to color textile fibers. This discovery will kick off a new area in the field of dye research and nowadays approximately all molecules used as dyes in the textile industry are synthetic with a strong fondness for diazo dyes [2-4]. In addition to this traditional application of dyes, other fields of interest make azo compounds a real source of hope,

\footnotetext{
*Correspondence: sopbue@yahoo.fr

${ }^{1}$ Laboratory of Applied Synthetic Organic Chemistry, Department of Chemistry, Faculty of Science, University of Dschang, P.O. Box 67, Dschang, Republic of Cameroon

Full list of author information is available at the end of the article
}

notably in pharmaceutical [5-7] and food industries [8, $9]$, and in dosimetry $[10,11]$. In general, azo dyes are highly preferred because they attach to the fibers by forming strong covalent bonds with the hydroxyl groups of the cellulose [12], so that the process of discoloration is very difficult under the conditions where textiles are washed $[13,14]$. It is also demonstrated that the degradation of the textile is linked to the action of the microorganisms that are attached to it and it is to remedy this problem that the textile industry makes increasing use of biocidal dyes such as diazo dyes [15]. The textile industry is also increasingly faced with the problem of treating wastewater polluted by the rest of the dyes that have not been fixed to the fibers during the coloring process [16]. Due to their structural complexity, azo dyes often 
have very low biodegradability and their biological treatments are usually expensive and generally inefficient [17]. For this purpose, electrochemical techniques are the most recommended alternative because of their high efficiency, their eco-friendliness and their relatively low cost [17]. We recently reported the synthesis of a cyclic holigomeric azo dye containing three $-\mathrm{N}=\mathrm{N}$ - units alternating with three fused thienocoumarins moieties in its structure and found to possess antioxidant properties. This means that it is capable to reduce an oxidant such as $\mathrm{Fe}^{3+}$ into $\mathrm{Fe}^{2+}$ through its diazo functionalities [18], justifying thereby the use of diazo compounds in chemotherapy treatments $[19,20]$. In addition, encouraged by previous promising results obtained from the biological activities studies of some of the azo compounds that we have recently reported [21], we therefore undertook to intensify our research for new azo compounds with good dyeing [5, 22], biological properties [6, 23], and which could also find interesting applications in solving some issues related to industrial environmental pollution [16]. In this work, we investigated the antimicrobial activities of five recently reported [24] azo compounds respectively on six bacterial and six fungal strains. On the other hand, in order to assess their possible applications in the textile industry waste water remediation, and the evidence concerning the mechanisms of biological electron-transfer processes we carried out the electrochemical characterization of these compounds, on the carbon electrode.

\section{Experimental}

\section{General information}

All melting points were corrected and were determined using an Electrothermal Melting Point Apparatus Model 9100, a Büchi 530 melting point apparatus and a Stuart Scientific Melting Point Apparatus SMP3. The Thin Layer Chromatography (TLCs) was carried out on Eastman Chromatogram Silica Gel Sheets $(13,181 ; 6060)$ with fluorescent indicators. A mixture of ethyl acetate and methylene chloride (7:3) was used as the eluent and iodine was used for the visualization of the chromatograms. The IR spectra were measured with a Fourier Transform Infrared spectrometer JASCO FT/IR-4100 and a Perkin Elmer FT-IR 2000 spectrometer. The UV spectra were recorded with a Beckman U-640 Spectrophotometer, using samples' solutions of concentration $2 \times 10^{-5} \mathrm{~mol} \mathrm{~L}^{-1}$. Combustion analyses were carried out with a Euro EA CHNSO analyser from Hekatech company, and the results were found to be in good agreement $( \pm 0.3 \%)$ with the calculated values. HREIMS were measured on mass spectrometer LCQ Classic with ESI Source from Thermo Fisher Scientific Company. ${ }^{1} \mathrm{H}-\mathrm{NMR}$ spectra were recorded in DMSO- $d_{6}$ with a $250 \mathrm{MHz}$ spectrometer Bruker AV III. ${ }^{13} \mathrm{C}$-NMR spectra were recorded in DMSO- $d_{6}$ with a $62.5 \mathrm{MHz}$ spectrometer Bruker AV III. Tetramethyl silane (TMS) was used as the internal reference.

\section{Preparation of the reagents and starting materials}

All the reagents mentioned in this work were purchased from Aldrich and Fluka and were used without further purification. Starting material $\mathbf{4}$ was prepared according to the procedures mentioned in the literature published earlier [25].

\section{Preparation of diazonium salt solution}

In a similar manner as described in [24] dry sodium nitrite $(2.07 \mathrm{~g}, 3 \mathrm{mmol})$ was slowly added over a period of $30 \mathrm{~min}$ to concentrated sulphuric acid $(10 \mathrm{~mL})$ with occasional stirring. The solution was cooled to $0-5{ }^{\circ} \mathrm{C}$. Compound 4 was dissolved in DMSO $(10 \mathrm{~mL})$ and cooled to $0-5{ }^{\circ} \mathrm{C}$. The nitrosyl sulphuric acid solution kept at $0-5{ }^{\circ} \mathrm{C}$ was added to the solution of 4 and the temperature was maintained between 0 and $5{ }^{\circ} \mathrm{C}$. The clear diazonium salt solution thus obtained consisting of the in situ-formed intermediate 5, was used immediately in the coupling reactions.

\section{General procedure for the preparation of the coupling products $7 a-e$}

Phenol derivatives $\mathbf{6 a - e}(3 \mathrm{mmol})$ were dissolved in DMSO $(10 \mathrm{~mL})$ and then cooled in an ice-bath at $0-5{ }^{\circ} \mathrm{C}$. The diazonium solution of $\mathbf{4}$ previously prepared was added drop wise over $1 \mathrm{~h}$, and then $15 \mathrm{~mL}$ of sodium acetate solution (10\%) was added to the mixture. The $\mathrm{pH}$ of the mixtures was in the range 9-11. The solid precipitate was collected on a filter and crystallised from methanol to give the title compounds 7 . The freshly prepared compounds were characterized by their physical, elemental and spectroscopic data which were found to be in full agreement with those published earlier [24].

3-[2-(2-hydroxy-1-naphthyl)diazenyl]-4H-benzo[f]thieno[3,4-c] chromen-4-one dihydrate, $7 \boldsymbol{a}$

Reaction of diazonium salt of $\mathbf{4}$ with $\mathbf{6 a}$ gave compound $7 \mathbf{a}$ as a red powder; yield $59 \%, 0.41 \mathrm{~g}, \mathrm{mp} 185.7^{\circ} \mathrm{C}$; IR $(\mathrm{KBr}) v_{\max }: 3558,3544(\mathrm{OH}), 3164,3153$ (Ar. C-H), 1718 $(\mathrm{C}=\mathrm{O}), 1617,1439,1412(\mathrm{~N}=\mathrm{N}) \mathrm{cm}^{-1}$. UV (THF) $\lambda_{\max } /$ nm (log $\varepsilon): 242$ (4.54), 254 (4.61), 277 (2.46), 290 (4.19), 298 (4.11), 335 (4.49), 356 (4.54), 374 (4.64), 391 (4.56). ${ }^{1} \mathrm{H}$ NMR $\left(250 \mathrm{MHz}, \mathrm{DMSO}-d_{6}\right): \delta_{\mathrm{H}} 7.21(1 \mathrm{H}, \mathrm{s}, 1-\mathrm{H})$, $7.61(1 \mathrm{H}, \mathrm{d}, J 8.9 \mathrm{~Hz}, 6-\mathrm{H}), 8.37(1 \mathrm{H}, \mathrm{d}, J 8.8 \mathrm{~Hz}, 7-\mathrm{H})$, $8.13(1 \mathrm{H}, \mathrm{d}, J 8.0 \mathrm{~Hz}, 8-\mathrm{H}), 7.71(1 \mathrm{H}, \mathrm{dd}, J 7.5$ and $7.5 \mathrm{~Hz}$, 9-H), $7.76(1 \mathrm{H}, \mathrm{dd}, J 7.5$ and $7.8 \mathrm{~Hz}, 10-\mathrm{H}), 8.63(1 \mathrm{H}, \mathrm{d}$, $J 9.0 \mathrm{~Hz}, 11-\mathrm{H}), 7.75\left(1 \mathrm{H}, \mathrm{d}, J 8.0 \mathrm{~Hz}, 3^{\prime}-\mathrm{H}\right), 7.98(2 \mathrm{H}, \mathrm{d}$, $J 8.0 \mathrm{~Hz}, 4^{\prime}-\mathrm{H}$ and $\left.5^{\prime}-\mathrm{H}\right), 7.50(1 \mathrm{H}$, dd, $J 7.5$ and $7.0 \mathrm{~Hz}$, $\left.6^{\prime}-\mathrm{H}\right), 8.00\left(1 \mathrm{H}\right.$, dd, $J 8.8$ and $\left.8.1 \mathrm{~Hz}, 7^{\prime}-\mathrm{H}\right), 7.33(1 \mathrm{H}, \mathrm{d}$, 
$\left.J 8.8 \mathrm{~Hz}, 8^{\prime}-\mathrm{H}\right), 2.51\left(1 \mathrm{H}, \mathrm{D}_{2} \mathrm{O}\right.$-exchangeable, $\left.\mathrm{OH}\right) .{ }^{13} \mathrm{C}$ NMR (62.50 MHz, DMSO- $\left.d_{6}\right): \delta_{C} 118.2(\mathrm{C}-1), 134.3$ (C-3), 116.3 (C-3a), 166.4 (C-4), 156.8 (C-5a), 125.6 (C-6 and C-3'), 139.5 (C-7), 131.4 (C-7a), 130.2 (C-8 and C-11b), 117.3 (C-9), 129.9 (C-10), 126.8 (C-11), 137.8 (C-1' and 11a), $103.3(\mathrm{C}-11 \mathrm{c}), 158.5\left(\mathrm{C}-2^{\prime}\right), 127.8\left(\mathrm{C}-4^{\prime}\right)$, $129.6\left(\mathrm{C}-4 \mathrm{a}^{\prime}\right), 128.7\left(\mathrm{C}-5^{\prime}\right), 118.9\left(\mathrm{C}-6^{\prime}\right), 132.7\left(\mathrm{C}-7^{\prime}\right)$, $120.8\left(\mathrm{C}-8^{\prime}\right), 147.7\left(\mathrm{C}-8 \mathrm{a}^{\prime}\right)$. MS, $m / z(\%)=236$ (47), 288 (30), 296 (100), 373 (40), 393 (50), 328 (100), 340 (22), 421 (22). Anal. Calcd for $\mathrm{C}_{25} \mathrm{H}_{18} \mathrm{~N}_{2} \mathrm{O}_{5} \mathrm{~S}$ (458.49): C, 65.50; H, 3.93; N, 6.11; S, 6.98. Found: C, 65.48; H, 3.91; N, 6.09; S, 6.96 .

\section{3-[2-(4-acetyl-3-hydroxy-2-naphthyl)diazenyl]-1-[2-(4-oxo-4 H-benzo[f]thieno[3,4-c]chromen-3-yl)diazenyl]-4H-benzo[f] thieno[3,4-c]chromen-4-one disulphate dihydrate, $\mathbf{7 b}$}

Reaction of diazonium salt of $\mathbf{4}$ with $\mathbf{6} \mathbf{b}$ gave compound $7 \mathrm{~b}$ as an orange powder; yield $28 \%, 0.38 \mathrm{~g}$, mp $194.9^{\circ} \mathrm{C}$; IR $(\mathrm{KBr}) v_{\max }: 3280(\mathrm{OH}), 3076($ Ar. $\mathrm{C}-\mathrm{H}), 1720(\mathrm{C}=\mathrm{O})$, $1619,1529,1438(\mathrm{~N}=\mathrm{N}) \mathrm{cm}^{-1}$. UV (THF) $\lambda_{\max } / \mathrm{nm}(\log$ ع): 240 (4.34), 253 (4.43), 293 (3.95), 328 (4.25), 343 (4.20), 360 (4.31), 373 (4.39), 388 (4.28). ${ }^{1} \mathrm{H}$ NMR $(250 \mathrm{MHz}$, DMSO- $\left.d_{6}\right): \delta_{\mathrm{H}} 3.45\left(3 \mathrm{H}, \mathrm{s}, \mathrm{CH}_{3}\right), 6.94\left(1 \mathrm{H}, \mathrm{s}, \mathrm{H}-1^{\prime \prime}\right), 7.41$ $\left(\mathrm{OH}\right.$, broad s, $\mathrm{D}_{2} \mathrm{O}$-exchangeable), $7.12\left(1 \mathrm{H}, \mathrm{s}, \mathrm{H}-1^{\prime}\right)$, $8.52(1 \mathrm{H}, \mathrm{dd}, J 10.53$ and $10.50 \mathrm{~Hz}, \mathrm{H}-9), 8.35(1 \mathrm{H}, \mathrm{dd}, J$ 7.75 and $\left.6.50 \mathrm{~Hz}, \mathrm{H}-9^{\prime \prime}\right), 8.00(1 \mathrm{H}, \mathrm{dd}, J 9.54$ and $7.50 \mathrm{~Hz}$, $\mathrm{H}-10), 7.88\left(1 \mathrm{H}\right.$, dd, J 8.75 and $\left.7.45 \mathrm{~Hz}, \mathrm{H}-6^{\prime}\right), 7.75(1 \mathrm{H}$, dd, $J 10.50$ and $\left.10.45 \mathrm{~Hz}, \mathrm{H}-7^{\prime}\right), 7.62(1 \mathrm{H}, \mathrm{dd}, J 8.00$ and $\left.7.70 \mathrm{~Hz}, \mathrm{H}-10^{\prime \prime}\right), 9.01(1 \mathrm{H}, \mathrm{d}, J 7.50 \mathrm{~Hz}, \mathrm{H}-11), 8.91(1 \mathrm{H}$, d, $\left.J 8.70 \mathrm{~Hz}, \mathrm{H}-5^{\prime}\right), 8.75\left(1 \mathrm{H}, \mathrm{d}, J 8.00 \mathrm{~Hz}, \mathrm{H}-11^{\prime \prime}\right), 8.18$ $\left(1 \mathrm{H}, \mathrm{d}, J 8.00 \mathrm{~Hz}, \mathrm{H}-6^{\prime \prime}\right), 7.67\left(1 \mathrm{H}, \mathrm{d}, J 11.50 \mathrm{~Hz}, \mathrm{H}-8^{\prime}\right)$, $7.55\left(1 \mathrm{H}, \mathrm{d}, J 8.00 \mathrm{~Hz}, \mathrm{H}-7^{\prime \prime}\right), 7.51(1 \mathrm{H}, \mathrm{d}, J 10.00 \mathrm{~Hz}$, $\mathrm{H}-8), 7.50(1 \mathrm{H}, \mathrm{d}, J 9.00 \mathrm{~Hz}, \mathrm{H}-7), 7.44(1 \mathrm{H}, \mathrm{d}, J 8.00 \mathrm{~Hz}$, $\left.\mathrm{H}-8^{\prime \prime}\right), 7.33(1 \mathrm{H}, \mathrm{d}, J 9.00 \mathrm{~Hz}, \mathrm{H}-6) .{ }^{13} \mathrm{C}$ NMR $(62.50 \mathrm{MHz}$, DMSO- $\left.d_{6}\right): \delta_{C} 164.2(\mathrm{CO}), 134.7$ (C-1), $145.0(\mathrm{C}-3), 115.4$ (C-3a), 157.0 (C-4), 148.5 (5a), 120.0 (C-6), 130.7 (C-7), 133.7 (C-7a), 131.6 (C-8), 122.2 (C-9), 127.8 (C-10), 124.8 (C-11), 131.0 (C-11a), 103.8 (C-11b), 114.3 (C-11c), 121.0 (C-1'), 137.0 (C-2'), 155.0 (C-3'), 113.7 (C-4'), 122.7 (C-4a'), $133.0\left(\mathrm{C}-5^{\prime}\right), 127.8\left(\mathrm{C}-6^{\prime}\right), 126.2\left(\mathrm{C}^{\prime} 7^{\prime}\right), 128.5$ (C-8'), 103.2 (C-8a'), $119.0\left(\mathrm{C}-1^{\prime \prime}\right), 139.1\left(\mathrm{C}-3^{\prime \prime}\right), 115.0$ $\left(\mathrm{C}-3 \mathrm{a}^{\prime \prime}\right), 156.6\left(\mathrm{C}-4^{\prime \prime}\right), 148.1\left(5 \mathrm{a}^{\prime \prime}\right), 123.6\left(\mathrm{C}-6^{\prime \prime}\right), 129.6$ $\left(\mathrm{C}-7^{\prime \prime}\right), 133.2\left(\mathrm{C}-7 \mathrm{a}^{\prime \prime}\right), 119.8\left(\mathrm{C}-8^{\prime \prime}\right), 121.0\left(\mathrm{C}-9^{\prime \prime}\right), 128.8$ $\left(\mathrm{C}-10^{\prime \prime}\right), 126.0\left(\mathrm{C}-11^{\prime \prime}\right), 130.8\left(\mathrm{C}-11 \mathrm{a}^{\prime \prime}\right), 103.5\left(\mathrm{C}-11 \mathrm{~b}^{\prime \prime}\right)$, $114.0\left(\mathrm{C}-11 \mathrm{c}^{\prime \prime}\right), 33.0\left(\mathrm{CH}_{3}\right)$. MS, $m / z(\%)=237(42), 250$
(62), 258 (100), 276 (45), 313 (17), 373 (80), 404 (25), 521 (22), 644 (40), 660 (10). Anal. Calcd for $\mathrm{C}_{42} \mathrm{H}_{30} \mathrm{~N}_{4} \mathrm{O}_{16} \mathrm{~S}_{4}$ (974.96): C, 51.74; H, 3.10; N, 5.75; S, 13.16. Found: C, $51.65 ; \mathrm{H}, 3.08 ; \mathrm{N}, 5.80 ; \mathrm{S}, 13.18$.

3-(2-\{3-acetyl-2-hydroxy-5,6-bis[2-(4-oxo-4H-benzo[f] thieno[3,4-c]chromen-3 yl)diazenyl]phenyl\}diazenyl)4H-benzo[f]thieno[3,4-c]chromen-4-one trisulphate, 7c

Reaction of diazonium salt of $\mathbf{4}$ with $\mathbf{6 c}$ gave compound 7c as an orange powder; yield 26\%, $0.65 \mathrm{~g}, \mathrm{mp} 200.2^{\circ} \mathrm{C}$; IR (KBr) $v_{\text {max }}: 3547(\mathrm{OH}), 1730(\mathrm{C}=\mathrm{O}), 1517,1435$ $(\mathrm{N}=\mathrm{N}) \mathrm{cm}^{-1}$. UV (THF) $\lambda_{\max } / \mathrm{nm}(\log \varepsilon): 236$ (5.33), 267 (5.01), 286 (4.98), 335 (5.18), 438 (4.28), 540 (3.33). ${ }^{1} \mathrm{H}$ NMR $\left(250 \mathrm{MHz}, \mathrm{DMSO}-d_{6}\right): \delta_{\mathrm{H}} 9.12\left(1 \mathrm{H}, \mathrm{br} \mathrm{s}, \mathrm{H}-4^{\prime}\right)$, $9.00\left(1 \mathrm{H}, \mathrm{d}, J 8.75 \mathrm{~Hz}, \mathrm{H}-7^{\prime \prime}\right), 8.83(1 \mathrm{H}, \mathrm{d}, J 9.50 \mathrm{~Hz}$,

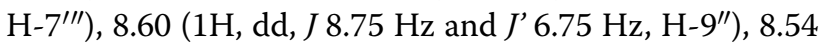
$\left(1 \mathrm{H}, \mathrm{dd}, J 9.50 \mathrm{~Hz}\right.$ and $\left.J 6.75 \mathrm{~Hz}, \mathrm{H}-10^{\prime \prime \prime}\right), 8.52(1 \mathrm{H}, \mathrm{d}, J$ $\left.11.75 \mathrm{~Hz}, 8^{\prime \prime \prime}\right), 8.50\left(1 \mathrm{H}, \mathrm{s}, \mathrm{H}-1^{\prime \prime}\right), 8.35(1 \mathrm{H}, \mathrm{d}, J 8.75 \mathrm{~Hz}$, H-6"), $8.12\left(1 \mathrm{H}, \mathrm{d}, J 8.75 \mathrm{~Hz}, \mathrm{H}-8^{\prime \prime}\right), 7.95(1 \mathrm{H}, \mathrm{d}, J 8.25 \mathrm{~Hz}$, $\left.\mathrm{H}-11^{\prime \prime}\right), 7.93(1 \mathrm{H}, \mathrm{d}, J 12.75 \mathrm{~Hz}, \mathrm{H}-7), 7.88$ (1H, dd, $J$ $8.00 \mathrm{~Hz}$ and $\left.J^{\prime} 7.75 \mathrm{~Hz}, \mathrm{H}-9\right), 7.82\left(1 \mathrm{H}, \mathrm{dd}, J 8.50 \mathrm{~Hz}\right.$ and $J^{\prime}$ $\left.8.25 \mathrm{~Hz}, \mathrm{H}-10^{\prime \prime}\right), 7.81(1 \mathrm{H}, \mathrm{s}, \mathrm{H}-1), 7.78(1 \mathrm{H}, \mathrm{d}, J 12.75 \mathrm{~Hz}$, $\mathrm{H}-6), 7.73\left(1 \mathrm{H}\right.$, dd, $J 7.50 \mathrm{~Hz}$ and $\left.J^{\prime} 6.50 \mathrm{~Hz}, \mathrm{H}-9^{\prime \prime \prime}\right), 7.74$ $\left(1 \mathrm{H}, \mathrm{d}, J 12.00 \mathrm{~Hz}, \mathrm{H}-11^{\prime \prime \prime}\right), 7.66(1 \mathrm{H}, \mathrm{dd}, J 13.00 \mathrm{~Hz}$ and $\left.J^{\prime} 7.25 \mathrm{~Hz}, \mathrm{H}-10\right), 7.60\left(1 \mathrm{H}, \mathrm{s}, \mathrm{H}-1^{\prime \prime \prime}\right), 7.58(1 \mathrm{H}, \mathrm{d}$, $\left.J 9.00 \mathrm{~Hz}, \mathrm{H}-6^{\prime \prime \prime}\right), 7.91$ (1H, d, J $\left.12.75 \mathrm{~Hz}, \mathrm{H}-11\right), 7.95$ $(1 \mathrm{H}, \mathrm{d}, J 8.25 \mathrm{~Hz}, \mathrm{H}-8), 2.42\left(3 \mathrm{H}, \mathrm{s}, \underline{\mathrm{CH}}_{3}-\mathrm{CO}\right) .{ }^{13} \mathrm{C} \mathrm{NMR}$ $\left(62.50 \mathrm{MHz}, \mathrm{DMSO}-d_{6}\right): \delta_{C} 125.8(\mathrm{C}-1), 132.6(\mathrm{C}-3)$, 114.4 (C-3a), 164.4 (C-4), 156.5 (C-5a), 121.8 (C-6), 137.8 (C-7), 131.5 (C-7a), 128.0 (C-8), 118.0 (C-9), 120.8 (C-10), 131.1 (C-11), 115.4 (C-11a), 148.2 (C-11b), 102.0 (C-11c), $133.0\left(\mathrm{C}-1^{\prime}\right), 157.0\left(\mathrm{C}-2^{\prime}\right), 122.6\left(\mathrm{C}-3^{\prime}\right), 131.0\left(\mathrm{C}-4^{\prime}\right), 138.2$ $\left(\mathrm{C}-5^{\prime}\right), 157.3\left(\mathrm{C}-6^{\prime}\right), 126.3\left(\mathrm{C}-1^{\prime \prime}\right), 155.0\left(\mathrm{C}-3^{\prime \prime}\right), 113.5$ $\left(\mathrm{C}-3 \mathrm{a}^{\prime \prime}\right), 165.0\left(\mathrm{C}-4^{\prime \prime}\right), 156.5\left(\mathrm{C}-5 \mathrm{a}^{\prime \prime}\right), 119.5\left(\mathrm{C}-6^{\prime \prime}\right), 130.3$ (C-7"), $131.0\left(\mathrm{C}-7 \mathrm{a}^{\prime \prime}\right), 127.5\left(\mathrm{C}-8^{\prime \prime}\right), 117.8\left(\mathrm{C}-9^{\prime \prime}\right), 123.6$ $\left(\mathrm{C}-10^{\prime \prime}\right), 129.5\left(\mathrm{C}-11^{\prime \prime}\right), 114.4\left(\mathrm{C}-11 \mathrm{a}^{\prime \prime}\right), 147.6\left(\mathrm{C}-11 \mathrm{~b}^{\prime \prime}\right)$, $100.4\left(\mathrm{C}-11 \mathrm{c}^{\prime \prime}\right), \quad 126.8\left(\mathrm{C}-1^{\prime \prime \prime}\right), \quad 156.1 \quad\left(\mathrm{C}-3^{\prime \prime \prime}\right), 113.8$ (C-3a' $\left.{ }^{\prime \prime \prime}\right), 163.7$ (C-4 $\left.{ }^{\prime \prime \prime}\right), 155.3\left(\mathrm{C}-5 \mathrm{a}^{\prime \prime \prime}\right), 120.0\left(\mathrm{C}-6^{\prime \prime \prime}\right), 136.8$

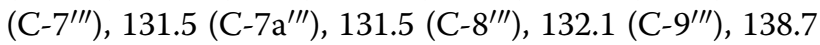
(C-10"' $), 136.2\left(\mathrm{C}-11^{\prime \prime \prime}\right), 103.7\left(\mathrm{C}-11 \mathrm{a}^{\prime \prime \prime}\right), 115.0\left(\mathrm{C}-11 \mathrm{~b}^{\prime \prime \prime}\right)$, $100.5\left(\mathrm{C}-11 \mathrm{c}^{\prime \prime \prime}\right), 165.0\left(\mathrm{COCH}_{3}\right), 25.8\left(\mathrm{COCH}_{3}\right) . \mathrm{MS}, \mathrm{m} / z$ $(\%)=234$ (23), 242 (63), 341 (74), 361 (54), 405 (17), 460 (100), 480 (24), 525 (10), 582 (9), 602 (4). Anal. Calcd for $\mathrm{C}_{53} \mathrm{H}_{32} \mathrm{~N}_{6} \mathrm{O}_{20} \mathrm{~S}_{6}$ (1265.24): C, 50.31; H, 2.55; N, 6.64; S, 15.21. Found: C, 50.29; H, 2.54; N, 6.62; S, 15.23 . 
3-(2-\{3-(tert-butyl)-2-hydroxy-5-methoxy-4,6-bis[2-(4-oxo -4H-benzo[f]thieno[3,4-c]chromen-3-yl)diazenyl]phenyl\} diazenyl)-4H-benzo[f]thieno[3,4-c]chromen-4-one sulphate monohydrate, 7d

Reaction of diazonium salt of $\mathbf{4}$ with $\mathbf{6} \mathbf{d}$ gave compound 7d as a red powder; yield 19\%, $0.43 \mathrm{~g}, \mathrm{mp} 214.8{ }^{\circ} \mathrm{C}$; IR $(\mathrm{KBr}) v_{\max }: 3310(\mathrm{OH}), 3056($ Ar. $\mathrm{C}-\mathrm{H}), 2960\left(\mathrm{C}_{\mathrm{sp} 3}-\mathrm{H}\right)$, 1734 (C=O), 1617, 1480, $1458(\mathrm{~N}=\mathrm{N}) \mathrm{cm}^{-1}$. UV (THF) $\lambda_{\max } / \mathrm{nm}(\log \varepsilon): 249$ (5.34), 252 (5.34), 290 (4.94), 335 (4.52), 356 (4.44), 372 (4.46). ${ }^{1} \mathrm{H}$ NMR (250 MHz, DMSO$\left.d_{6}\right): \delta_{\mathrm{H}} 7.65\left(1 \mathrm{H}, \mathrm{s}, 1-\mathrm{H}^{\prime \prime}\right), 7.81\left(1 \mathrm{H}, \mathrm{m}, 6-\mathrm{H}^{\prime \prime}\right), 8.64(1 \mathrm{H}, \mathrm{m}$, $\left.7-\mathrm{H}^{\prime \prime}\right), 8.97\left(1 \mathrm{H}, \mathrm{d}, J 8.0 \mathrm{~Hz}, 8-\mathrm{H}^{\prime \prime}\right), 7.87(1 \mathrm{H}, \mathrm{d}, J 7.5 \mathrm{~Hz}$, 9- $\left.\mathrm{H}^{\prime \prime}\right), 8.46\left(1 \mathrm{H}, \mathrm{dd}, J 7.5\right.$ and $\left.8.3 \mathrm{~Hz}, 10-\mathrm{H}^{\prime \prime}\right), 7.77(1 \mathrm{H}, \mathrm{m}$, $\left.11-\mathrm{H}^{\prime \prime}\right), 7.84(1 \mathrm{H}, \mathrm{s}, 1-\mathrm{H}), 7.93(1 \mathrm{H}, \mathrm{d}, J 8.0 \mathrm{~Hz}, 6-\mathrm{H}), 8.58$ $(1 \mathrm{H}, \mathrm{d}, J 9.3 \mathrm{~Hz}, 7-\mathrm{H}), 8.76(1 \mathrm{H}, \mathrm{dd}, J 7.0$ and $8.6 \mathrm{~Hz}, 8-\mathrm{H})$, $7.80(1 \mathrm{H}, \mathrm{dd}, J 7.5$ and $7.5 \mathrm{~Hz}, 9-\mathrm{H}), 8.34(1 \mathrm{H}, \mathrm{m}, 10-\mathrm{H})$, $7.90(1 \mathrm{H}, \mathrm{d}, J 8.0 \mathrm{~Hz}, 11-\mathrm{H}), 7.90\left(1 \mathrm{H}, \mathrm{s}, 1^{\prime \prime \prime}-\mathrm{H}\right), 7.73(1 \mathrm{H}$, $\left.\mathrm{d}, J 8.0 \mathrm{~Hz}, 6^{\prime \prime \prime}-\mathrm{H}\right), 8.32\left(1 \mathrm{H}, \mathrm{m}, 7^{\prime \prime \prime}-\mathrm{H}\right), 8.10(1 \mathrm{H}, \mathrm{m}$, $\left.8^{\prime \prime \prime}-\mathrm{H}\right), 8.00\left(1 \mathrm{H}, \mathrm{d}, J 6.8 \mathrm{~Hz}, 9^{\prime \prime \prime}-\mathrm{H}\right), 8.44\left(1 \mathrm{H}, \mathrm{m}, 10^{\prime \prime \prime}\right.$ $\mathrm{H}), 8.38\left(1 \mathrm{H}, \mathrm{m}, 11^{\prime \prime \prime}-\mathrm{H}\right), 3.60\left(3 \mathrm{H}, \mathrm{s}, \mathrm{OCH}_{3}\right), 3.21(9 \mathrm{H}, \mathrm{s}$, $\left.\mathrm{CH}_{3}\right) .{ }^{13} \mathrm{C}$ NMR $\left(62.50 \mathrm{MHz}\right.$, DMSO- $\left.d_{6}\right): \delta_{\mathrm{C}} 126.6(\mathrm{C}-1)$, 147.5 (C-3), 113.0 (C-3a), 163.2 (C-4), 156.7 (C-5a), 121.0 (C-6), 137.6 (C-7), 130.7 (C-7a), 128.8 (C-8), 118.3 (C-9), 122.6 (C-10), 130.2 (C-11), 154.8 (C-11a), 115.3 (C-11b), 102.1 (C-11c), $114.6\left(\mathrm{C}-1^{\prime}\right), 149.0\left(\mathrm{C}-2^{\prime}\right), 121.5\left(\mathrm{C}-3^{\prime}\right)$, $119.1\left(\mathrm{C}-4^{\prime}\right), 138.3\left(\mathrm{C}-5^{\prime}\right), 102.0\left(\mathrm{C}-6^{\prime}\right), 126.8\left(\mathrm{C}-1^{\prime \prime}\right), 147.5$ $\left(\mathrm{C}-3^{\prime \prime}\right), 113.2\left(\mathrm{C}-3 \mathrm{a}^{\prime \prime}\right), 164.3\left(\mathrm{C}-4^{\prime \prime}\right), 156.1\left(\mathrm{C}-5 \mathrm{a}^{\prime \prime}\right), 119.4$ $\left(\mathrm{C}-6^{\prime \prime}\right), 135.9\left(\mathrm{C}-7^{\prime \prime}\right), 131.2\left(\mathrm{C}-7 \mathrm{a}^{\prime \prime}\right), 127.2\left(\mathrm{C}-8^{\prime \prime}\right), 117.6$ $\left(\mathrm{C}-9^{\prime \prime}\right), 123.6\left(\mathrm{C}-10^{\prime \prime}\right), 129.4\left(\mathrm{C}-11^{\prime \prime}\right), 155.0\left(\mathrm{C}-11 \mathrm{a}^{\prime \prime}\right), 114.6$

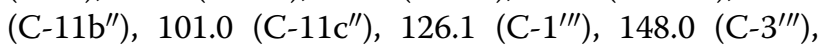
114.4 (C-3a $\left.\mathrm{a}^{\prime \prime \prime}\right), 163.2\left(\mathrm{C}-4^{\prime \prime \prime}\right), 155.8\left(\mathrm{C}-5 \mathrm{a}^{\prime \prime \prime}\right), 121.0\left(\mathrm{C}-6^{\prime \prime \prime}\right)$, $137.2\left(\mathrm{C}-7^{\prime \prime \prime}\right), 131.5\left(\mathrm{C}-7 \mathrm{a}^{\prime \prime \prime}\right), 128.0\left(\mathrm{C}-8^{\prime \prime \prime}\right), 117.6\left(\mathrm{C}-9^{\prime \prime \prime}\right)$,

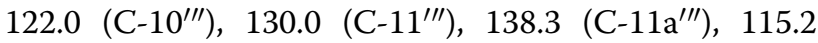
$\left(\mathrm{C}-11 \mathrm{~b}^{\prime \prime \prime}\right), 103.7\left(\mathrm{C}-11 \mathrm{c}^{\prime \prime \prime}\right), 56.0\left(\mathrm{OCH}_{3}\right), 18.6\left(3 \mathrm{CH}_{3}\right)$, $25.7\left(\underline{\mathrm{C}}\left(\mathrm{CH}_{3}\right)_{3}\right)$. MS, $m / z(\%)=1131$ (7), 1113 (21), 1015 (4), 985 (5), 852 (17), 799 (100), 754 (54), 736 (30), 275 (39), 261 (100). Anal. Calcd for $\mathrm{C}_{56} \mathrm{H}_{38} \mathrm{~N}_{6} \mathrm{O}_{13} \mathrm{~S}_{4}$ (1131.19): C, 59.46; H, 3.39; N, 7.43; S, 11.34. Found: C, 59.45; H, 3.41; N, 7.45; S, 11.35 .

\section{3-\{2-[3-(tert-butyl)-4-hydroxy-5-methylphenyl] diazenyl\}-4H-benzo[f]thieno[3,4-c]chromen-4-one dihydrate, $7 e$}

Reaction of diazonium salt of $\mathbf{4}$ with $\mathbf{6 e}$ gave compound $7 \mathbf{e}$ as a red powder; yield $69 \%, 0.33 \mathrm{~g}, \mathrm{mp} 217.6{ }^{\circ} \mathrm{C}$; IR $(\mathrm{KBr}) v_{\max }: 3177\left(\right.$ Ar. C-H), $2954\left(\mathrm{C}_{\mathrm{sp} 3}-\mathrm{H}\right), 1718(\mathrm{C}=\mathrm{O})$, 1633, 1479, $1454(\mathrm{~N}=\mathrm{N}) \mathrm{cm}^{-1}$. UV (THF) $\lambda_{\max } / \mathrm{nm}(\log$ ع): 241 (4.50), 259 (4.51), 290 (4.18), 398 (5.05), 403 (5.05),
409 (5.06), 441.5 (5.06), 423 (5.03). ${ }^{1} \mathrm{H}$ NMR (250 MHz, DMSO- $\left.d_{6}\right): \delta_{\mathrm{H}} 7.23(1 \mathrm{H}, \mathrm{s}, 1-\mathrm{H}), 7.48(1 \mathrm{H}, \mathrm{d}, J 7.8 \mathrm{~Hz}$, 6-H), $8.34(1 \mathrm{H}, \mathrm{d}, J 7.8 \mathrm{~Hz}, 7-\mathrm{H}), 8.50(1 \mathrm{H}, \mathrm{d}, J 7.7 \mathrm{~Hz}$, 8-H), $8.33(1 \mathrm{H}, \mathrm{dd}, J 7.5$ and $7.0 \mathrm{~Hz}, 9-\mathrm{H}), 7.30(1 \mathrm{H}, \mathrm{dd}$, $J 6.7$ and $7.4 \mathrm{~Hz}, 10-\mathrm{H}), 8.68(1 \mathrm{H}, \mathrm{d}, J 7.5 \mathrm{~Hz}, 11-\mathrm{H}), 7.65$ $\left(1 \mathrm{H}, \mathrm{s}, 2^{\prime}-\mathrm{H}\right), 7.30\left(1 \mathrm{H}, \mathrm{s}, 6^{\prime}-\mathrm{H}\right), 3.56\left(3 \mathrm{H}, \mathrm{s}, \mathrm{CH}_{3}\right), 3.01$ $\left(9 \mathrm{H}, \mathrm{s}, \mathrm{CH}_{3}\right) .{ }^{13} \mathrm{C}$ NMR $\left(62.50 \mathrm{MHz}, \mathrm{DMSO}-d_{6}\right): \delta_{\mathrm{C}} 119.2$ (C-1), 132.4 (C-3), 115.6 (C-3a), 164.5 (C-4), 155.2 (C-5a), 126.3 (C-6), 139.7 (C-7), 133.1 (C-7a), 130.1 (C-8), 120.7 (C-9), 128.0 (C-10), 125.5 (C-11), 135.2 (C-11a), 130.0 (C-11b), 104.0 (C-11c), $114.5\left(\mathrm{C}-1^{\prime}\right), 119.3\left(\mathrm{C}-2^{\prime}\right), 122.4$ $\left(\mathrm{C}-3^{\prime}\right), 148.7\left(\mathrm{C}-4^{\prime}\right), 105.8\left(\mathrm{C}-5^{\prime}\right), 108.8\left(\mathrm{C}-6^{\prime}\right), 12.8\left(\mathrm{CH}_{3}\right)$, $18.8\left(3 \mathrm{CH}_{3}\right), 26.0\left(\underline{\mathrm{C}}\left(\mathrm{CH}_{3}\right)_{3}\right) . \mathrm{MS}, m / z(\%)=1347(70)$, 1231 (2), 827 (4), 726 (100), 663 (17), 325 (100). Anal. Calcd for $\mathrm{C}_{26} \mathrm{H}_{26} \mathrm{~N}_{2} \mathrm{O}_{5} \mathrm{~S}$ (478.56): C, 65.25; H, 5.48; N, 5.85; S, 6.70. Found: C, 65.23; H, 5.51; N, 5.84; S, 6.72.

\section{Cyclic voltammetry}

Voltammetric measurements were carried out using a $\mu$-Autolab (Ecochemie, Holland) controlled by the GPES electrochemical software. The working electrode was a glassy carbon electrode $(0.3 \mathrm{~mm}$ diameter $)$ properly polished using alumina paste prior to experiments. A Platinum gauze and a $\mathrm{Ag} / \mathrm{AgCl}(3 \mathrm{M} \mathrm{KCl})$ were used as counter and reference electrodes, respectively. Cyclic voltammograms were obtained with a scan rate of $50 \mathrm{mV} \mathrm{s}^{-1}$. Experiments were carried out at room temperature and in the presence of $0.1 \mathrm{M} \mathrm{KCl}$ or $0.02 \mathrm{M}$ $\mathrm{H}_{2} \mathrm{SO}_{4}$ as supporting electrolyte, unless otherwise stated.

\section{Biological assay \\ Bacterial strains and culture media}

The studied microorganisms were both reference (from the American Type Culture Collection) and clinical (from Institut Pasteur and Ecole Nationale Vétérinaire d'Alford, France) strains of Providencia stuartii, Escherichia coli, Pseudomonas aeruginosa, Enterobacter aerogenes, Klebsiella pneumoniae, Candida albicans, Crytococcus neoformans and Trichophyton terrestre. Also, included were two clinical isolates of Trichophyton ajeloi and Trichophyton violaceum, obtained at the Laboratory of Microbiology and Antimicrobial Substances, University of Dschang and two clinical isolates of Candida parapsilosis and Staphylococcus aureus collected from Pasteur Centre (Yaounde-Cameroon). The bacterial and fungal species were grown at $37 / 28{ }^{\circ} \mathrm{C}$ and maintained on nutrient agar (NA, Conda, Madrid, Spain) and Sabouraud Dextrose Agar (SDA, Conda) slants respectively. 


\section{Preparation of microbial inoculum}

The inocula of yeasts and bacteria were prepared from overnight cultures by picking numerous colonies and suspending them in sterile saline $(\mathrm{NaCl})$ solution $(0.90 \%)$. Absorbance was red at $530 \mathrm{~nm}$ for yeasts or at $600 \mathrm{~nm}$ for bacteria. Adjustment was done with a saline solution to match that of a 0.50 McFarland standard solution. From the prepared microbial solutions, other dilutions with saline solution were prepared to give a final concentration of $10^{6}$ yeast cells $/ \mathrm{ml}$ and $10^{6} \mathrm{CFU} / \mathrm{ml}$ for bacteria $[19,26]$.

Conidia suspensions of dermatophyte species were prepared from 10 days old cultures respectively. The number of conidia was determined using a spectrophotometer and adjusted with sterile saline $(\mathrm{NaCl})$ solution $(0.90 \%)$ to an absorbance of 0.600 at $450 \mathrm{~nm}$ corresponding to a final concentration of about $1 \times 10^{5}$ spores $/ \mathrm{ml}$ [27].

\section{Antimicrobial activity}

The antimicrobial activity was investigated by determining the minimum inhibitory concentrations (MICs), minimum bactericidal concentrations (MBC) and minimum fungicidal concentrations (MFCs).

MICs were determined by broth micro dilution [28, 29]. Stock solutions of the pure compounds were prepared in $10 \% \mathrm{v} / \mathrm{v}$ aqueous dimethylsulfoxide (DMSO) solution (Fisher chemicals, Strasbourg, France) at concentration of $1024 \mu \mathrm{g} / \mathrm{ml}$. This was twofold serially diluted in Mueller-Hinton Broth (MHB) for bacteria and Sabouraud
Dextrose Broth (SDB) for fungi to obtain a concentration range of $512-0.25 \mu \mathrm{g} / \mathrm{ml}$. For every experiment, a sterility check (10\% aqueous DMSO and medium), negative control (10\% aqueous DMSO, medium and inoculum) and positive control (10\% aqueous DMSO, medium, inoculum and water-soluble antibiotics) were included. One hundred microliters of each concentration was introduced into a well (96-wells microplate) containing $90 \mu \mathrm{l}$ of SDB or MHB and $10 \mu \mathrm{l}$ of inoculum was added to obtain a final concentration range of $256-0.125 \mu \mathrm{g} / \mathrm{ml}$. The plates were covered with a sterile lid, and incubated on the shaker at $37^{\circ} \mathrm{C}$ for $24 \mathrm{~h}$ (bacteria), $48 \mathrm{~h}$ (yeasts) or 5 days (dermatophytes). MICs were assessed visually after the corresponding incubation period and were taken as the lowest sample concentration at which there was no growth or virtually no growth. The assay was repeated thrice.

For the minimum microbicidal concentration (MMC) determination, $10 \mu \mathrm{l}$ aliquots from each well that showed no growth of microorganism were plated on MuellerHinton Agar or Sabouraud Dextrose Agar and incubated at $37^{\circ} \mathrm{C}$ for $24 \mathrm{~h}$ (bacteria), $48 \mathrm{~h}$ (yeasts) and at $28^{\circ} \mathrm{C}$ for 10 days (dermatophytes). The lowest concentration that yielded no growth after the sub-culturing was taken as the MBCs or MFCs. Ciprofloxacin (Sigma-Aldrich, Steinheim, Germany) for bacteria, nystatin (Sigma-Aldrich, Steinheim, Germany) for yeasts and griseofulvin (SigmaAldrich, Steinheim, Germany) for dermatophytes were used as positive controls.<smiles>CC(=O)c1c(O)ccc2ccccc12</smiles>
1<smiles>O=[N+]([O-])[C@H]1C=C(O)C=CC1</smiles>

$6 a$<smiles>CCOC(=O)CC#N</smiles>

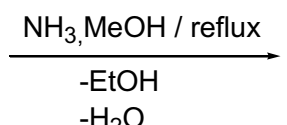

$-\mathrm{H}_{2} \mathrm{O}$<smiles>Cc1c(C#N)c(=O)oc2ccc3ccccc3c12</smiles>

3

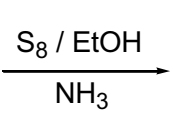

$\mathrm{Ar}-\mathrm{OH}$<smiles>COc1ccc2ccccc2c1-c1csc(N)c1C</smiles>

4 $\left(0-5{ }^{\circ} \mathrm{C}\right)$ 7 $-5^{\circ} \mathrm{C}$ 5<smiles>Oc1ccc2ccccc2c1</smiles><smiles>CC(=O)c1c(O)ccc2ccccc12</smiles>

$6 b$<smiles>CC(=O)c1ccccc1O</smiles>

$6 c$<smiles>COc1ccc(O)c(C(C)(C)C)c1</smiles>

$6 d$<smiles>Cc1cccc(C(C)(C)C)c1O</smiles>

$6 e$

Scheme 1 Reactions'sequences to compounds 7 


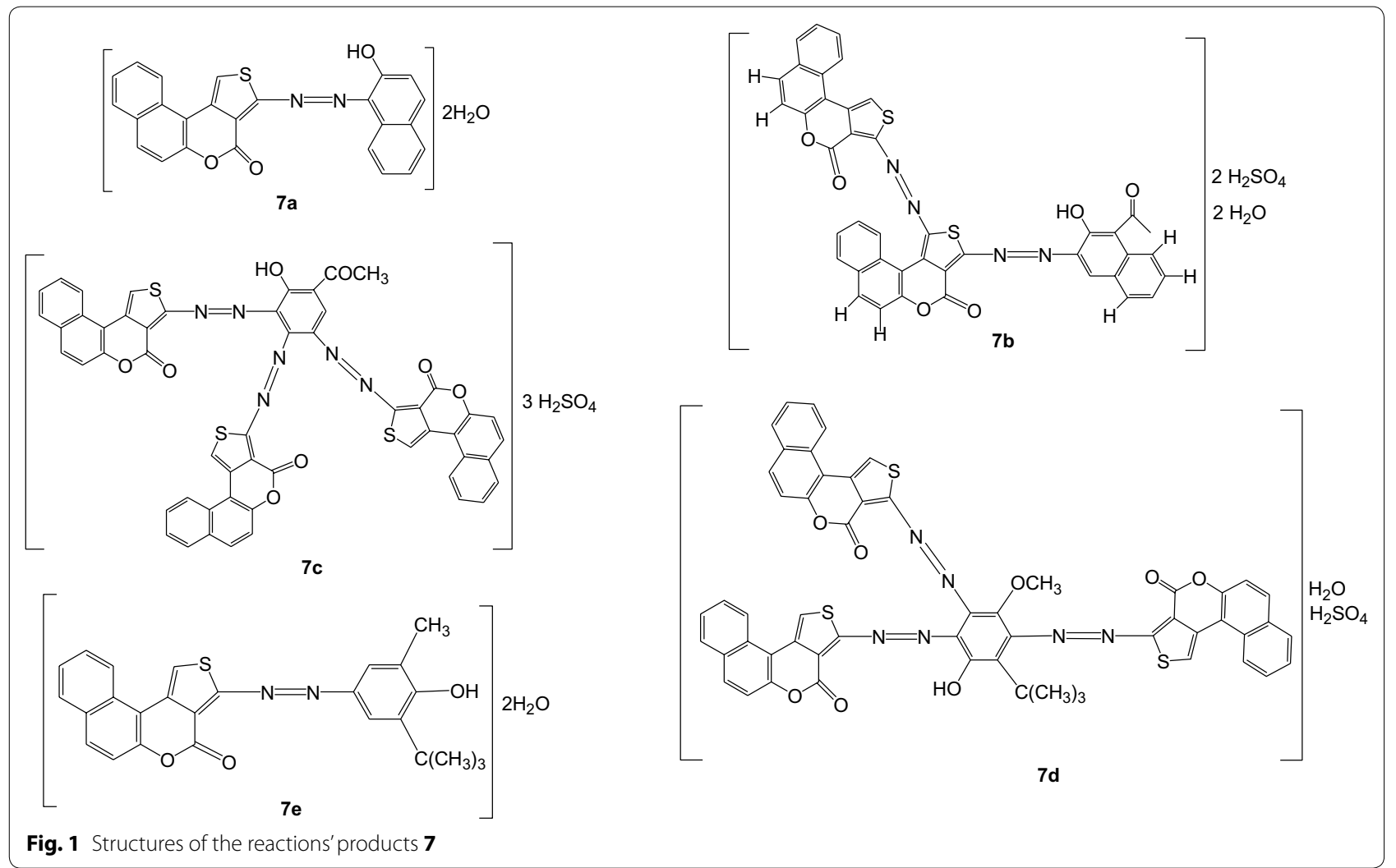

Fig. 1 Structures of the reactions' products 7
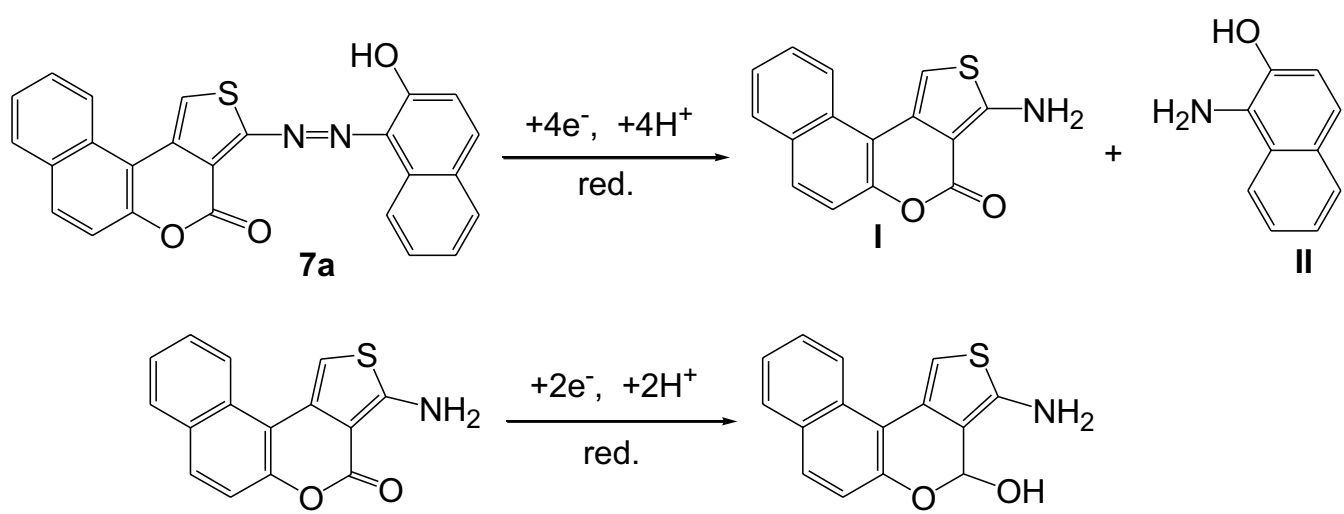

I

III

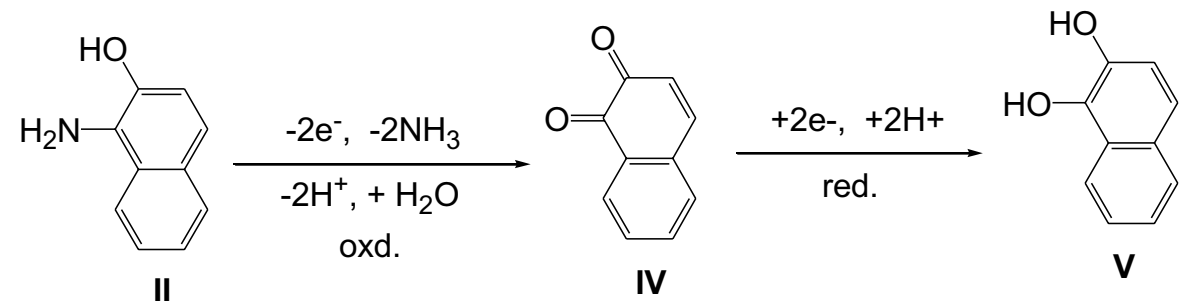

Scheme $\mathbf{2}$ Reduction and oxidation mechanisms of compound $\mathbf{7 a}$ and subsequent intermediates 


\section{Results and discussion}

\section{Chemistry}

The first step in the preparation of the coupling components was the synthesis of the relevant 2-aminothiophene 4 using the Gewald reaction [30, 31]. The synthesis of the thienocoumarins 4 from the multicomponent condensation of ketones, cyanoacetate and elemental sulphur was originally published early (Scheme 1) [25].

Compound 4 was diazotized using nitrosyl sulphuric acid in the cold and coupled with the phenolic compounds $6 \mathbf{a}-\mathbf{e}$ to yield the azo dyes $7 \mathbf{a}-\mathbf{e}$ (Scheme 1 and Fig. 1) as previously described [24].

\section{Redox behaviors of the azo dyes Compound $7 a$}

Two distinct reduction peaks (Ic and IIc) were observed for the electroreduction of azo dyes $7 \mathbf{a}$, the first one Ic at $0.0046 \mathrm{mv}$ due to the cleavage of the azo group, $-\mathrm{N}=\mathrm{N}-$ to give the reductive amines products I and II (Scheme 2). The second peak IIc at $0.3 \mathrm{mv}$, due to the reduction of $\mathrm{C}=\mathrm{O}$ group of the intermediate $\mathbf{I}$ to $\mathrm{CH}_{2} \mathrm{OH}$ in product III (Scheme 2). Since the $-\mathrm{N}=\mathrm{N}-$ group is more susceptible to reduction than the $\mathrm{C}=\mathrm{O}$ groups, $-\mathrm{N}=\mathrm{N}-$ group is reduced at less negative potential than other sites [32].

The highly reactive intermediate product II provide quasi reversible oxidation-reduction peaks (Fig. 2) during reverse and subsequent forward scans due to the formation of oxidation product, 1,2-naphthaquinone IV and its subsequent reduction to dihydroxynaphthalene $\mathbf{V}$ (Scheme 2).

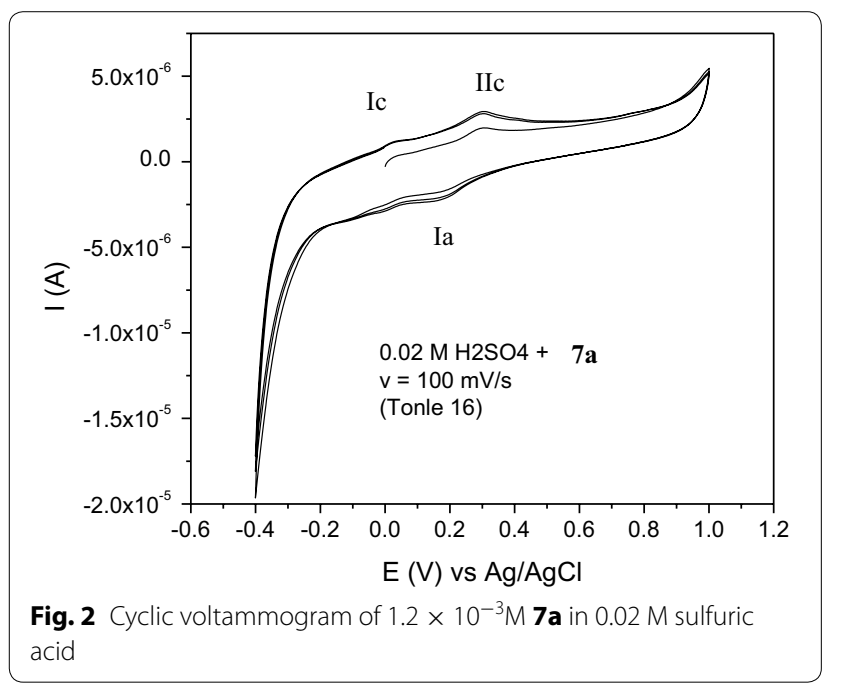

\section{Compound $7 b$}

In the cyclic voltammograms of $\mathbf{7 b}$ (Fig. 3), four peaks were recorded, of which three cathodic peaks (Ic, IIc and IIIC) in the forward scan and one anodic peak (Ia) in the reverse scan, indicating the quasi-reversible electrochemical nature of the dye (Fig. 3). The anodic peak only appeared in the subsequent scan after the reduction step. Hence, this peak was obviously due to the corresponding oxidation of the reduction products. As reported in previous literatures [33], azo dyes with a hydroxyl group adjacent to an azo bridge can be reduced to yield the corresponding amine, which is most likely to be reoxidized in the return scan. The first peak $(-0.045 \mathrm{~V})$ can be therefore attributed to the reduction of the $-\mathrm{N}=\mathrm{N}-$ bridge adjacent to the hydroxyl group (Scheme 3).

The second peak $(0.27 \mathrm{~V})$ can therefore be attributed to the reduction of the second $-\mathrm{N}=\mathrm{N}$ - bridge of compound A. The last peak $(0.936 \mathrm{~V})$ may be attributed to the catalytic hydrogen reduction of the carbonyl group $(\mathrm{C}=\mathrm{O})$ of the intermediate $\mathbf{B}$ to give compound $\mathbf{E}$ (scheme 3). The highly reactive intermediate product $\mathbf{E}$ provides a quasi reversible oxidation-reduction peaks $(-0.045 \mathrm{~V})$ during reverse and subsequent forward scans (scheme 3 ).

\section{Compound $7 c$}

To understand the electrochemical behavior of dye $7 \mathbf{c}$, the $\mathrm{CV}$ studies were carried out using solution with and without dye taking Ag wire as working electrode (Fig. 4). The potential scan used for the study was $-0.5-1.0 \mathrm{~V}$. The dye solution, both showed single anodic peak approximately at $-0.0526 \mathrm{~V}$ and also one cathodic peak

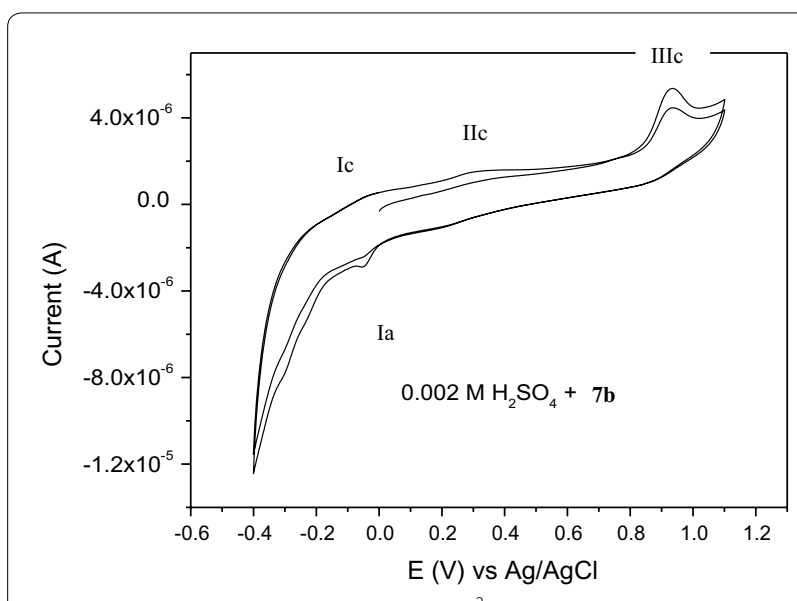

Fig. 3 Cyclic voltammogram of $2 \times 10^{-3} \mathrm{M} \mathbf{7 b}$ in $0.02 \mathrm{M}$ sulfuric acid 


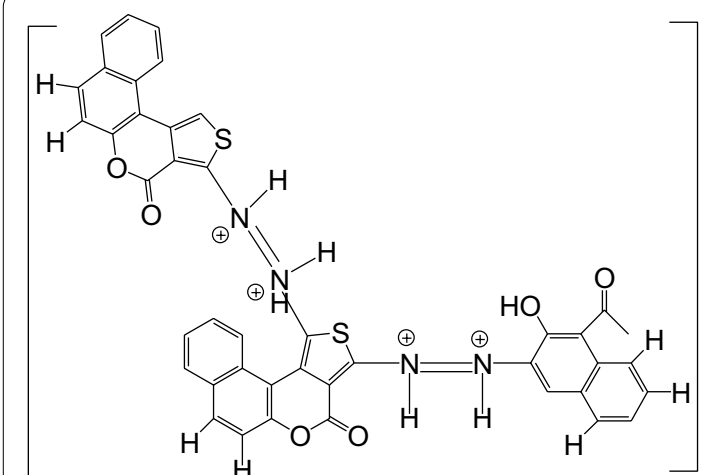

$7 b$<smiles>Nc1sc([NH+]=Nc2scc3c2c(=O)oc2ccc4ccccc4c23)c2c1oc1ccc3ccccc3c12</smiles>

A<smiles>CC(=O)c1c(O)c(N)cc2ccccc12</smiles>

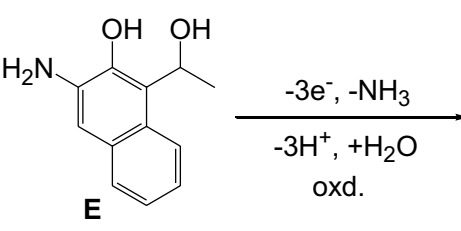

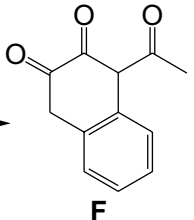

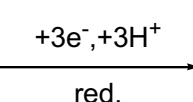<smiles>CC(O)c1c(O)c(O)cc2ccccc12</smiles>

G

Scheme 3 Reduction and oxidation mechanisms of compound $\mathbf{7 b}$ and subsequent intermediates

at approximately $0.168 \mathrm{~V}$. The voltammetric curve of compound $7 \mathrm{c}$ showed that the reduction takes place in one step and one irreversible cathodic wave was observed in cyclic voltammogram (Fig. 4).

The anodic peak is due to the reduction of compound $7 \mathbf{c}$ to compounds $\mathbf{B}$ and $\mathbf{C}$ through the intermediate $\mathbf{A}$. The first step of the reduction process does not however require external supply of protons, because the starting reagent $7 \mathbf{c}$ is pre-protonated by the sulfuric acid crystallites. The clivage of the three azo bridges in the second step of the reduction requires six protons to yield compounds $\mathbf{B}$ and $\mathbf{C}$. Intermediate $\mathbf{B}$ subsequently undergoes a quasi-reversible oxidation-reduction process during reverse and subsequent forward scans. The probable mechanism for the reduction process is displayed in scheme 4.

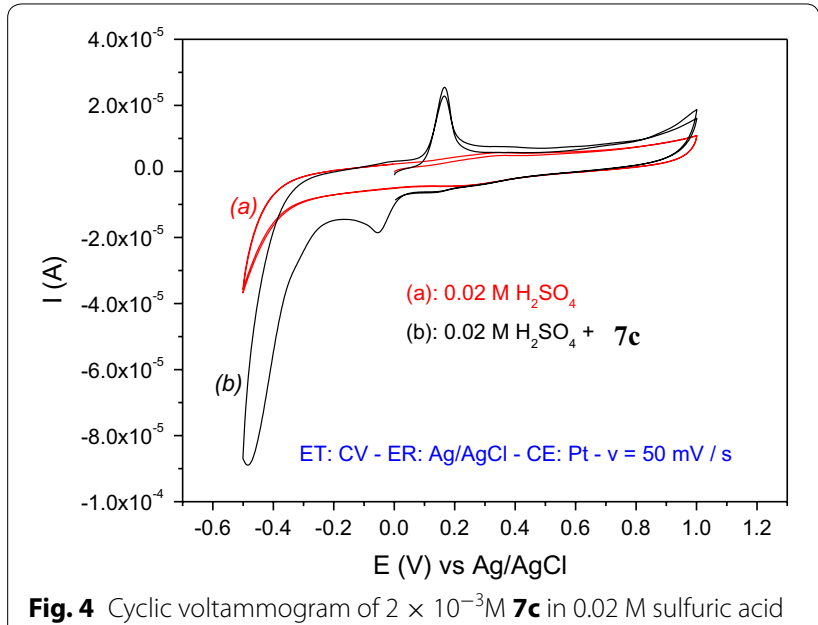

Fig. 4 Cyclic voltammogram of $2 \times 10^{-3} \mathrm{M}$ 7c in $0.02 \mathrm{M}$ sulfuric acid 


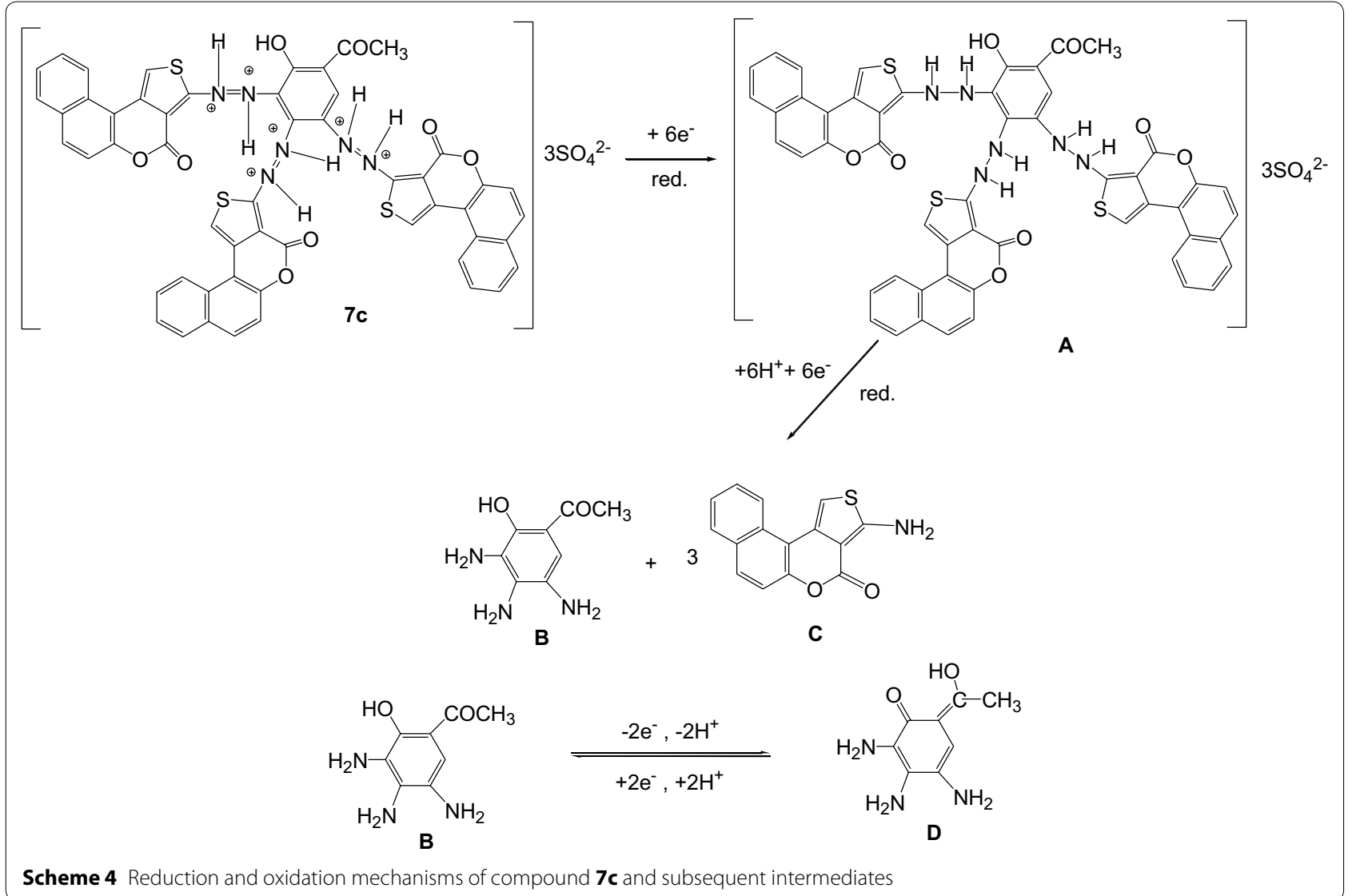

\section{Compound $7 e$}

The voltammetric behavior of compound 7e was studied (Fig. 5). The single cathodic wave observed on the voltammograms of $7 \mathbf{e}$ apparently corresponds to the reduction of the azo group and appeared in the range $0.4-0.6 \mathrm{mV}$.

The reduction process results in the clivage of the azo bridge leading to the formation of compounds I and II (Scheme 5). The intermediate II, further undergoes oxidation to afford compound III which in turn is reduced to give compound IV during reverse and subsequent forward scan.

\section{Antimicrobial activity}

The azo compounds $7 \mathbf{a}-\mathbf{e}$ and the entire precursors 1-4 and $\mathbf{6 a}-\mathbf{e}$ were examined in vitro against bacterial and fungal species and the results are depicted in Table 1. All the compounds showed different degree of antimicrobial activities against the tested fungal and bacterial pathogens. Enterobacter aerogenes and E. coli were the most sensitive microorganisms while Trichophyton terrestre

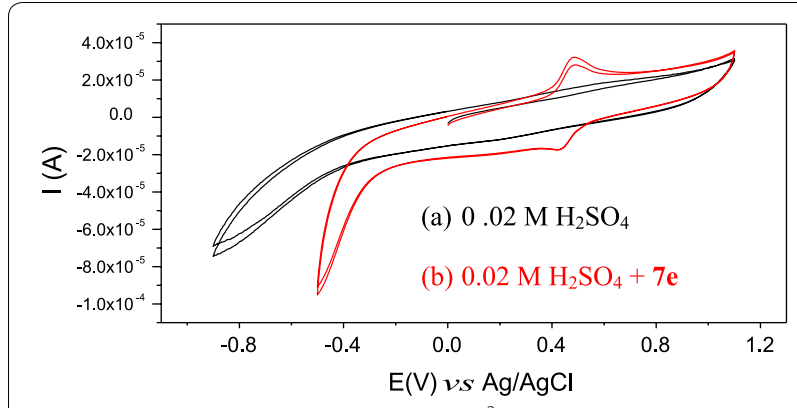

Fig. 5 Cyclic voltammograms of $2 \times 10^{-3} \mathrm{M}$ 7e in $0.02 \mathrm{M}$ sulfuric acid

and Trichophyton violaceum were the most resistant. In general, bacterial species were more sensitive than fungal species; this can be due to the structural complexity of fungi compared with that of bacteria.

No activity was noted with compounds $\mathbf{1}$ and $\mathbf{2}$ against all the tested microorganisms (not shown). However, the Knoevenagel condensation [34] of $\mathbf{1}$ and $\mathbf{2}$ afforded the coumarin intermediate $\mathbf{3}$ which exhibited a relatively 

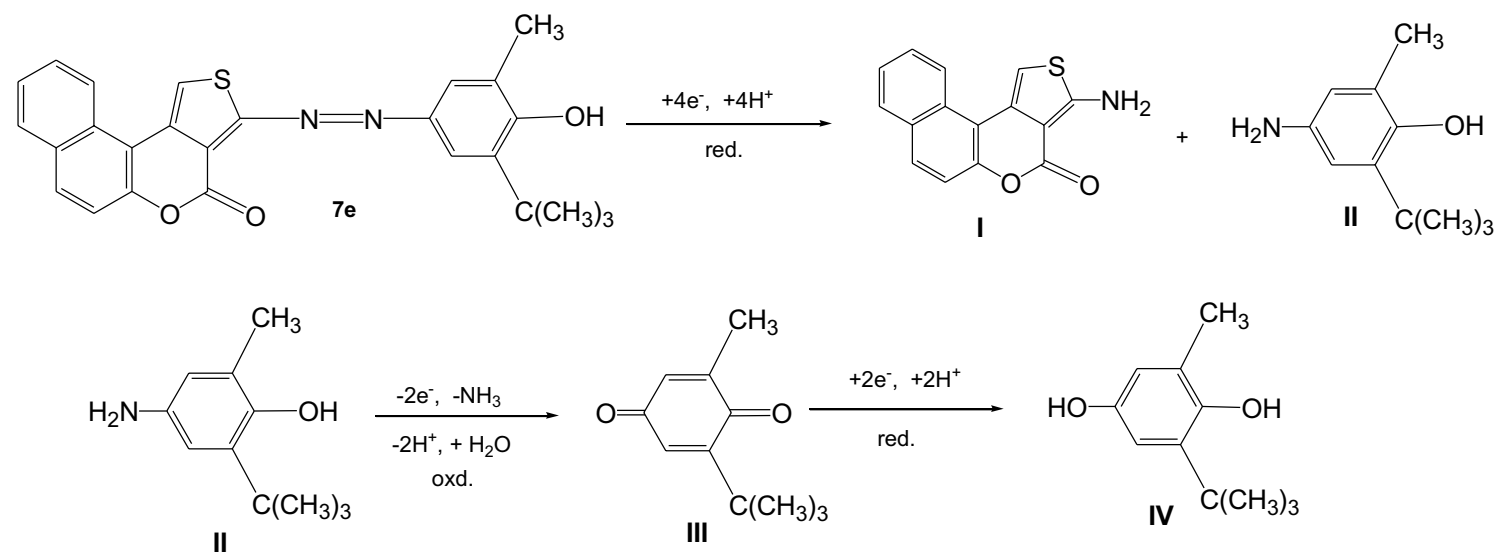

Scheme 5 Reduction and oxidation mechanisms of compound $\mathbf{7 e}$ and subsequent intermediates

higher antimicrobial activity. Moreover, diazotisation of compound $\mathbf{4}$ with nitrosyl sulphuric acid and coupling with phenol derivatives resulted into an effective enhancement of the antimicrobial activity in compounds $7 \mathbf{a}, \mathbf{c}-\mathbf{e}$. Compounds $\mathbf{6 a - e}$ and $7 \mathbf{a}-\mathbf{e}$ showed selective activities; their inhibitory effects being noted respectively on $10 / 12$ (83.33\%), 6/12 (50.00\%), 4/12 (33.33\%), $12 / 12(100.00 \%), 5 / 12(41.66 \%)$ and $12 / 12(100 \%), 9 / 12$ (75.00\%), 12/12 (100\%), 12/12 (100.00\%), 12/12 (100\%) of the studied microorganisms. Compounds $\mathbf{6 d}$ and $7 \mathbf{a}, \mathbf{c}-\mathbf{e}$ showed antimicrobial properties against all the tested microorganisms ( $\mathrm{MIC}=2-256 \mu \mathrm{g} / \mathrm{ml})$. This finding suggests the antibacterial and antifungal potencies of these compounds. The lowest MIC value for these tested compounds $(2 \mu \mathrm{g} / \mathrm{ml})$ was obtained with compound $7 \mathbf{a}$ on Cryptococcus neoformans. The antimicrobial activities of compound $7 \mathbf{a}(\mathrm{MIC}=2-16 \mu \mathrm{g} / \mathrm{ml})$ were in some cases equal or more important than those of ciprofloxa$\operatorname{cin}(\mathrm{MIC}=2-8 \mu \mathrm{g} / \mathrm{ml})$ and nystatin $(\mathrm{MIC}=2-4 \mu \mathrm{g} / \mathrm{ml})$ used as reference drugs; highlighting its good antimicrobial potency. The results of the MMC values indicate that most of them are not more than fourfold their corresponding MICs. This proves that the killing effects of many tested compounds could be expected on the most sensitive strains [35].

The present study highlighted the antimicrobial activity of the azo compounds and their precursors against the microorganisms including bacterial and fungal species. Although azo compounds have been reported to possess interesting activity against a wide range of microorganisms [35-37], no study has hitherto been reported on the activity of the azo dyes $7 \mathbf{a}-\mathbf{e}$ and their precursors $\mathbf{3}$, 4 and $6 \mathbf{a}-\mathbf{e}$ against these types of pathogenic strains. As far as the structure-activity relationship is concerned, some structural features that might have influenced the antimicrobial activity of these azo compounds can be drawn from the comparison of the chemical structures of the screened compounds with different activities. Compound $7 \mathbf{a}$ was the most active azo compound, followed by $7 \mathbf{e}, \mathbf{7 c}, \mathbf{7 d}$ and $\mathbf{7 b}$. It appears that, in general, hydroxyl, 2-tertbutyl, 4-methoxy and aromatic groups play a greater role in increasing the antimicrobial activity based on the substitution patterns of the aromatic rings.

\section{Effects of azo functionality to the activity of compounds 7}

It results from Table 1 that the microbicidal activity of compound 7c on P. stuartii ATCC29916, Klebsiella pneumoniae ATCC11296, Trichophyton terrestre E1501, Trichophyton violaceum, Trichophyton ajeloi, Candida parapsilosis, Candida albicans ATCC 9002 and Cryptococcus neoformans IP95026 is entirely due to the presence of azo groups in the molecule. The microbicidal activity of compound 7e on Providencia stuartii ATCC29916, Klebsiella pneumoniae ATCC11296, Staphylococcus aureus, Trichophyton terrestre E1501, Trichophyton violaceum, Trichophyton ajeloi, Candida parapsilosis, Candida albicans ATCC 9002, Candida parapsilosis ATCC 22019 and Cryptococcus neoformans IP95026 is also attributed to the presence of the azo function in the molecule. Conversely, it was noted that the azo functionality inhibited the activity on E. coli ATCC10536 and Enterobacter aerogenes ATCC13048 with the transformation of the starting materials 4 and $\mathbf{6 b}$ into compound $\mathbf{7 b}$. These observations corroborate previous reports related to the role played by the azo function in similar biological active substances [38]. 


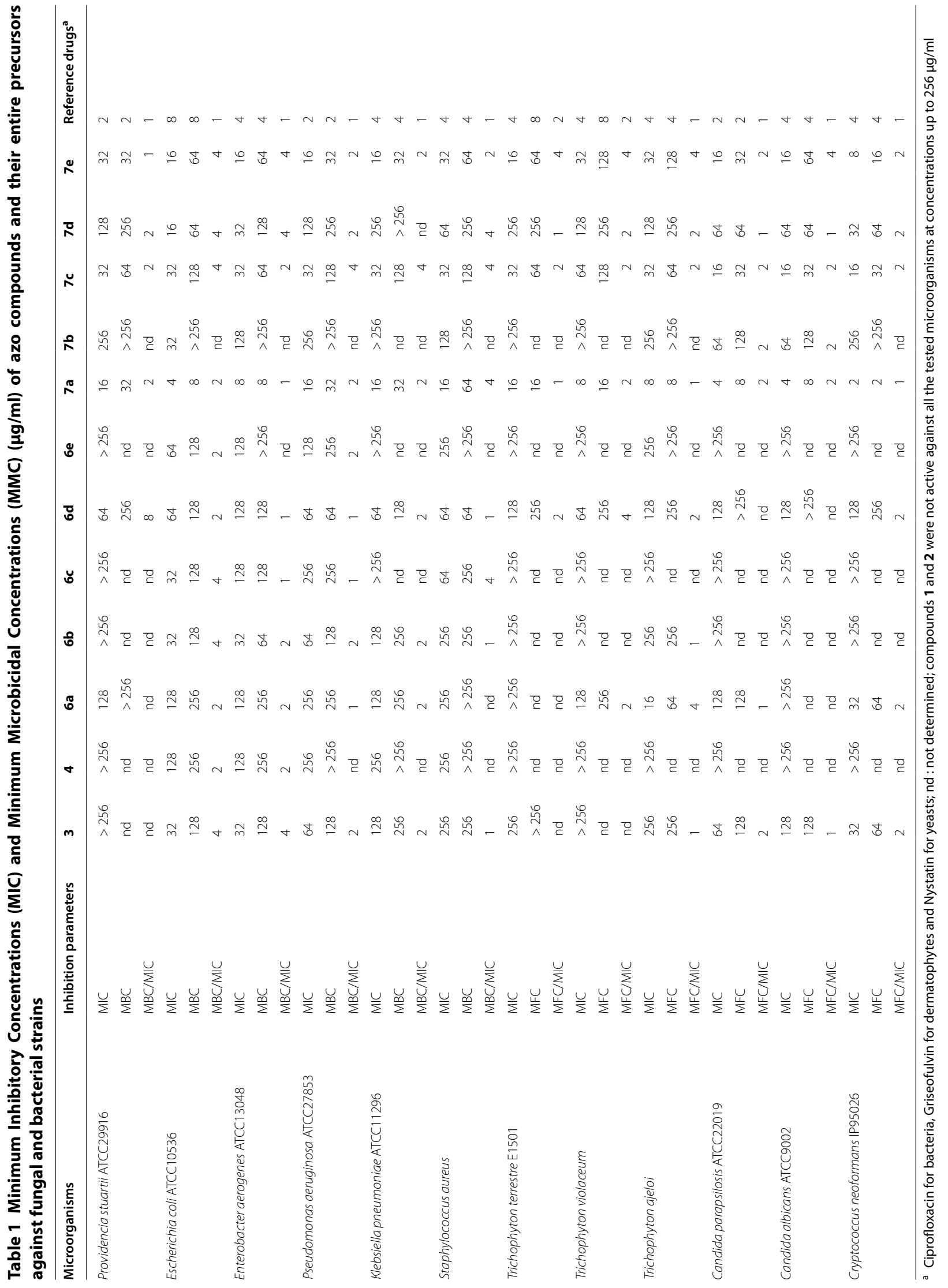




\section{Conclusion}

Thienylazoaryls compounds $7 \mathbf{a}-\mathbf{e}$ were synthesized, studied electrochemically at a glassy carbon electrode and preliminarily evaluated for their in vitro antimicrobial properties. The reduction of the azo group in compounds 7 exhibited different behavior due to the constitutional structure of the dyes. It was observed that pre-protonated forms get involved in the reduction step and a different number of protons are involved. The protonation reaction was facilitated owing to the increasing electron density of the azo group, due to the donating effect of the hydroxyl group at the ortho position. Then, a decrease in the electron density on electroactive functional group led to an easy reduction process. Compounds $7 \mathbf{a}, \mathbf{c}-\mathbf{e}$ as well as their precursors $\mathbf{3}$ and $\mathbf{6} \mathbf{d}$ displayed good antibacterial and antifungal activities. The presence of hydroxyl, 2-tertbutyl, 4-methoxy and aromatic groups could explain their good antibacterial and antifungal activities. Further studies are needed to determine additional physicochemical and biological parameters in order to provide a deeper insight into the structure-activity relationship and to optimize the potentials of these compounds.

\section{Abbreviations}

T.L.C: thin layer chromatography; IR: infra-red; UV: ultra-violet; HREIMS: high resolution electron impact mass spectrometry; ${ }^{1} \mathrm{H}-\mathrm{NMR}$ : proton nuclear magnetic resonance; 13C-NMR: thirteen carbon nuclear magnetic resonance; DMSO: dimethylsulfoxide; TMS: tetramethylsilane; mp: melting points; THF: tetrahydrofuran; MIC: minimum inhibitory concentration; MBC: minimum bactericidal concentration; MFC: minimum fungicidal concentration; MHB: Mueller-Hinton Broth; SDB: sabouraud dextrose broth; MMC: minimum microbicidal concentration; CV: cyclic voltammogram.
\end{abstract}

\section{Authors' contributions}

All authors equally contributed to the paper and have given approval to the final version of the paper. All authors read and approved the final manuscript.

\begin{abstract}
Author details
${ }^{1}$ Laboratory of Applied Synthetic Organic Chemistry, Department of Chemistry, Faculty of Science, University of Dschang, P.O. Box 67, Dschang, Republic of Cameroon. ${ }^{2}$ Department of Organic Chemistry, University of Yaounde I, P.O. Box 812, Yaounde, Republic of Cameroon. ${ }^{3}$ Laboratory of Microbiology and Antimicrobial Substances, Department of Biochemistry, Faculty of Science, University of Dschang, PO Box 067, Dschang, Republic of Cameroon. ${ }^{4}$ Laboratory of Analytical and Molecular Chemistry, Faculty Polydisciplinaire of Safi, University Cadi Ayyad Marrakech, Route Sidi Bouzid BP 4162, Safi 46000,
\end{abstract} Morocco.

\section{Acknowledgements}

ESF gratefully acknowledges financial support from DAAD (Grant No A/09/07421) for a scholarship. ADN is grateful to his supervisors Prof. Dr. J. S. Glaser and Dr. R. Marx for helpful suggestions in performing the NMR experiments. The necessary NMR spectrometers were provided by the Bavarian NMR Center (Bayerisches NMR-Zentrum). Additional financial supports for the work were obtained from the University of Dschang research grant committee and the Cameroonian Ministry of Higher Education special research allocation.

\section{Competing interests}

The authors declare that they have no competing interests.

Availability of data and materials

With the authors.
Consent for publication

Not applicable.

Ethics approval and consent to participate

Not applicable.

\section{Publisher's Note}

Springer Nature remains neutral with regard to jurisdictional claims in published maps and institutional affiliations.

Received: 6 September 2017 Accepted: 10 November 2017

Published online: 21 November 2017

\section{References}

1. Filarowski A (2010) Perkin's mauve: the history of the chemistry. Resonance 15(9):850-855

2. Bae JS, Freeman HS (2007) Aquatic toxicity evaluation of new direct dyes to the Daphnia magna. Dyes Pigm 73(1):81-85

3. Elisangela F, Andrea Z, Fabio DG, Cristiano RM, Regina DL, Artur CP (2009) Biodegradation of textile azo dyes by a facultative Staphylococcus arlettae strain VN-11 using a sequential microaerophilic/aerobic process. Int Biodeter Biodegrad 63:280-288

4. Rathod KM, Thakre NS (2013) Synthesis and antimicrobial activity of azo compounds containing m-cresol moiety. Chem Sci Trans 2(1):25-28

5. Gaffer HE, Fouda MMG, Khalifa ME (2016) Synthesis of some novel 2-amino-5-arylazothiazole disperse dyes for dyeing polyester fabrics and their antimicrobial activity. Molecules 21:122-131

6. Bae JS, Freeman HS, El-Shafei A (2003) Metallization of non-genotoxic direct dyes. Dyes Pigm 57(2):121-129

7. Garg HG, Praksh C (1972) Preparation of 4-arylazo-3,5-disubstituted(2H)-1,2,6-thiadiazine 1,1-dioxides. J Med Chem 15(4):435-436

8. Węglarz-Tomczak E, Górecki $Ł$ (2012) Azo dyes-biological activity and synthetic strategy. CHEMIK 66(12):1298-1307

9. Menek N, Turgut G, Mustafa O (1999) Electrochemical behaviour of hexa[4-(phenylazo)phenoxy] cyclotriphasphazene. Turk J Chem 23:423-427

10. Khazaal FA, Mohammed HJ (2016) Novel electrochemical behavior of 3-(5-(3-Methyl-1-phenylpyrazolazo)-1-nitroso-2-naphthol and use it for spectrophotometric determination of iron(III) in blood samples. Der Pharma Chemica 8(13):123-132

11. Goyal RN, Verma MS, Singhal NK (1998) Voltammetric investigations of the reduction of direct orange-31 a bisazo dye. Croat Chem Acta 3:715-726

12. Fox MR, Sumner HH (1986) The dyeing of cellulose fibers. Dyer's Company Publication Trust, Bradford, p 149-159

13. Shaikh A, Meshram JS (2015) Design, synthesis and pharmacological assay of novel azo derivatives of dihydropyrimidinones. Cogent Chemistry 1(1019809):1-9

14. Sabnis RW (2016) The Gewald reaction in dye chemistry. Colora Technol 132:49-82

15. Khedr AM, Gaber M, Abd El-Zaher EH (2011) Synthesis, structural characterization, and antimicrobial activities of $\mathrm{Mn}(\mathrm{II}), \mathrm{CO}(\mathrm{II}), \mathrm{Ni}(\mathrm{II}), \mathrm{Cu}(\mathrm{II})$ and Zn(II) complexes of triazole-based azodyes. Chin J Chem 29:1124-1132

16. Jain R, Sharma N, Radhapyari K (2009) Removal of hazardous azo dyes, metanil yellow from industrial wastewater using electrochemical technique. Eur Water 27(28):43-52

17. Kariyajjanavar P, Narayana J, Nayaka YA, Umanaik M (2010) Electrochemical degradation and cyclic voltammetric studies of textile reactive azo dye cibacron navy WB. Portugaliae Electrochimica Acta 28(4):265-277

18. Fondjo ES, Djeukoua DKS, Tamokou J-D-D, Tsemeugne J, Kouamo S, Ngouanet D, Chouna JR, Nkeng-Efouet-Alango P, Kuiate J-R, Ngongang NA, Sondengam BL (2016) Synthesis, characterization, antimicrobial and antioxidant activities of the homocyclotrimer of 4-oxo-4 h-thieno[3,4-C] chromene-3-diazonium sulfate. Open Med Chem J 10:21-32

19. Tamokou J-D-D, Tsemeugne J, Sopbué FE, Sarkar P, Kuiate J-R, Djintchui AN, Sondengam BL, Bag PK (2016) Antibacterial and cytotoxic activities 
and SAR of some azo compounds containing thiophene backbone. Pharmacologia 7(4):182-192

20. Sahu DK, Ghosh G, Sahoo J, Kumar PS (2013) Evaluation of antimicrobial activity of some newly synthesized azo compounds derived from thiobarbituric acid. Int J Adv Chem Sci Appl 1(1):25-27

21. Sopbué FE, Tsemeugne J, Tamokou J-D-D, Djintchui AN, Kuiaté J-R, Sondengam BL (2013) Synthesis and antimicrobial activities of some novel thiophene containing azo compounds. Heterocycl Commun 19:253-259

22. Al-Mousawi SM, El-Apasery MA, Mahmoud HM (2013) Disperse Dyes based on aminothiophenes: their dyeing applications on polyester fabrics and their antimicrobial activity. Molecules 18:7081-7092

23. Ono M, Wada Y, Wu Y, Nemori R, Jinbo Y, Wang H, Lo KM, Yamaguchi N, Brunkhorst B, Otomo H, Wesolowski J, Way JC, Itoh I, Gillies S, Chen LB (1997) FP-21399 blocks HIV envelope protein-mediated membrane fusion and concentrates in lymph nodes. Nat Biotechnol 15(4):343-348

24. Tsemeugne J, Fondjo SE, Ngongang AD, Sabnis RW, Sondengam BL (2017) Coupling of the diazonium sulphate of 3-amino-4H-benzo[f] thieno[3,4-c] $(2 \mathrm{H})$ chromen-4-one with phenol and naphthol derivatives in varied stoichiometries. Trends Org Chem 18:55-69

25. Fondjo SE, Döpp D, Henkel G (2006) Reactions of some annelated 2-aminothiophenes with electron poor acetylenes. Tetrahedron 62:7121-713

26. National Committee for Clinical Laboratory Standards (1992) Reference method for broth dilution antifungal susceptibility testing of yeast; approved standard, 2nd (eds) M27-A2. NCCLS, Wayne

27. Venugopal PV, Venugopal TV (1992) In vitro susceptibility of dermatophytes to imidazoles. Indian J Dermatol 37:34-35

28. Nyaa TB, Tapondjou AL, Barboni L, Tamokou JD, Kuiate JR, Tane P, Park $H$ (2009) NMR assignment and antimicrobial/antioxidant activities of $1 \beta$-hydroxyeuscaphic acid from the seeds of Butyrospermum parkii. J Nat Prod Sci 15:76-82
29. Fogue SP, Lunga KP, Sopbue FE, Tamokou JD, Thaddée B, Tsemeugne J, Tienga TA, Kuiate JR (2012) Substituted 2-aminothiophenes: antifungal activities and effect on Microsporum gypseum protein profile. Mycoses Diagn Ther Prophyl Fungal Dis 55:310-317

30. Gewald K (1961) Zur Reaktion von a-Oxo-mercaptanen mit Nitrilen. Angew Chem 73(3):114-115

31. Gewald K (1965) Heterocycles from CH acidic nitriles. VIII. 2-aminothiophene from a-oxo mercaptans and methylene-active nitriles. Chem Ber 98:3571-3577

32. Semiha Ç, Ender B, Mustafa O, Çiğdem A (2005) Electrochemical and spectroscopic study of 4-(Phenyldiazenyl)-2-\{[tris(hydroxymethyl)methyl] amino- methylene\}cyclohexa-3,5-dien-1(2H)-one mechanism of the azo and imine electroreduction. J Braz Chem Soc 16(4):711-717

33. Jiefei Y, Jinping J, Zifeng M (2004) Comparison of electrochemical behavior of hydroxyl-substituted and nonhydroxyl-substituted azo dyes at a glassy carbon electrode. J Chin Chem Soc 51:1319-1324

34. Knoevenagel E (1896) Über eine Darstellungsweise des Benzylidenacetessigesters. Ber Dtshe Chem Ges 29:172-174

35. Tamokou JD, Mpetga Simo DJ, Lunga PK, Tene M, Tane P, Kuiate JR (2012) Antioxidant and antimicrobial activities of ethyl acetate extract, fractions and compounds from the stem bark of Albizia adianthifolia (Mimosoideae). BMC Complement Altern Med 12(99):1-10

36. Awad IM, Aly AA, Abdel AMA, Abdel ARA, Ahmed SH (1998) Synthesis of some 5-azo-(4'-substituted benzene-sulphamoyl)-8-hydroxyquinolines with antidotal and antibacterial activities. J Inorg Biochem 33(2):77-89

37. Samadhiya S, Halve H (2001) Synthetic utility of schiff bases as potential herbicidal agends. Orient J Chem 17:119-122

38. Mkpenie V, Ebong G, Obot IB, Abasiekong B (2008) Evaluation of the effect of azo group on the biological activity of 1-(4-methylphenylazo)2-naphthol. E J Chem 5:431-434

\section{Submit your manuscript to a SpringerOpen ${ }^{\circ}$ journal and benefit from:}

- Convenient online submission

- Rigorous peer review

- Open access: articles freely available online

- High visibility within the field

- Retaining the copyright to your article

Submit your next manuscript at $\boldsymbol{\nabla}$ springeropen.com 